\title{
Combined Analyses of Ion Beam Synthesized Layers in Porous Silicon
}

\author{
A.R. RAmos ${ }^{a}$, F. PÁSZTi ${ }^{c}$, Z.E. Horváth ${ }^{d}$, É. VÁZSONYI $^{d}$,
}

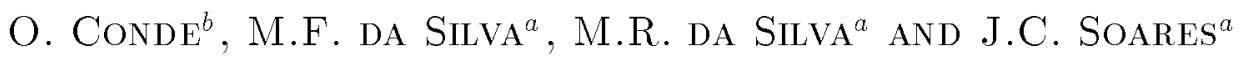

${ }^{a}$ ITN-Inst. Tecnológico e Nuclear, Estr. Nacional 10, 2686-953 Sacavém, Portugal and Centro de Física Nuclear da Universidade de Lisboa

Av. Prof. Gama Pinto 2, 1649-003, Lisboa, Portugal

${ }^{b}$ FCUL-Fac. de Ciências da Univ. de Lisboa, Dep. Física

Ed. C1, 1749-016, Lisboa, Portugal

${ }^{c}$ KF KI-Res. Inst. for Particle and Nuclear Physics

P.O. BOX 49, 1525, Budapest, Hungary

${ }^{d}$ MTA-Res. Inst. for Technical Phys. and Materials Science

P.O. BOX 49, 1525, Budapest, Hungary

High dose ion implantation was used to form polycrystalline silicide films on porous silicon with different native concentrations of light impurities ( $\mathrm{C}$ and $\mathrm{O}$ ). Porous silicon layers several $\mu \mathrm{m}$ thick were implanted with $170 \mathrm{keV} \mathrm{Cr}{ }^{+}$ions to fluences of $3 \times 10^{17}$ ions $/ \mathrm{cm}^{2}$ both at room temperature and $450^{\circ} \mathrm{C}$. Similar samples were implanted with $100 \mathrm{keV} \mathrm{Co}{ }^{+}$ions to fluences of $2 \times 10^{17}$ ions $/ \mathrm{cm}^{2}$ at room temperature, $350^{\circ} \mathrm{C}$, and $450^{\circ} \mathrm{C}$. The formed silicide compounds were studied by Rutherford backscattering spectrometry, elastic recoil detection, glancing incidence X-ray diffraction, and four point-probe sheet resistance measurements. Selected Co implanted samples were analysed by cross-section transmission electron microscopy. Results show that the light impurities were partially expelled from the forming silicide layer. Combining cross-section transmission electron microscopy with ion beam methods it was possible to show that, in the implanted region, the porous structure collapses and densifies during implantation, but the underlying porous silicon remains intact. The layer structure, as well as the quality and type of the formed silicide, were found to depend on the original impurity level, implantation temperature, and annealing.

PACS numbers: 61.10.-i, 61.18.Bn, 61.43.Gt, 68.55.Ln 


\section{Introduction}

Porous silicon (PS) is extensively investigated for its electroluminescence property [1]. Its use could allow the integration of optical and electronic units into a single device with conventional technology. A basic requirement is the formation of electric contacts on PS: conductive films and contacts are necessary to provide interconnection between devices and the outside world. Given the structural and compositional properties of PS, ion beam synthesized (IBS) refractory metal silicides are a privileged choice for metallization.

Previous experiments revealed that PS densifies under ion bombardment [2]. If the implanted ions react with silicon, as the ones routinely used in silicide formation do, e.g. 100-200 keV Ti, W, and Co ions [3], preparation of compact silicide contacts on PS may be achieved in one single step. Cr was the first species chosen: PS usually has a high native concentration of contaminants, mostly $\mathrm{C}$ and $\mathrm{O}$, and it is known that implanted $\mathrm{Cr}$ can, even in silica, react with silicon to form silicide [4]. However, Cr forms a relatively high resistivity semiconducting disilicide $(\approx 1500 \mu \Omega \mathrm{cm}$ ). Therefore, a second batch of samples was implanted with Co in order to study the possibility of forming a lower resistivity metallic silicide already after the implantation, thus avoiding the need for a high temperature annealing that would destroy the PS [1].

\section{Experimental}

Three different kinds of 5-10 $\mu \mathrm{m}$ thick PS layers were prepared by anodic etching. Sample preparation details can be found in Refs. [5, 6]. Chosen samples were pre-oxidized right after manufacturing by annealing at $300^{\circ} \mathrm{C}$ for $60 \mathrm{~min}$ in an $\mathrm{N}_{2}$ atmosphere with $\approx 1 \% \mathrm{O}_{2}$. Between preparation and implantation, the samples were kept in containers at either normal, argon, or pentane atmosphere. Argon was found to be effective in delaying the $\mathrm{O}$ uptake, whereas the samples kept in pentane oxidized more quickly. One batch of samples was implanted with $170 \mathrm{keV} \mathrm{Cr}{ }^{+}$ions, at $5 \mu \mathrm{A} / \mathrm{cm}^{2}$ current density and $15^{\circ}$ tilt, up to a fluence of $3 \times 10^{17}$ ions $/ \mathrm{cm}^{2}$ at either room temperature (RT) or $450^{\circ} \mathrm{C}$. The latter samples were annealed at $700^{\circ} \mathrm{C}$ for $90 \mathrm{~min}$ and the chosen ones were further annealed at $1000^{\circ} \mathrm{C}$ for $15 \mathrm{~min}$. A second batch of samples was implanted with $100 \mathrm{keV} \mathrm{Co}{ }^{+}$ ions, at $3 \mu \mathrm{A} / \mathrm{cm}^{2}$ current density and $15^{\circ}$ tilt, up to a fluence of $2 \times 10^{17}$ ions $/ \mathrm{cm}^{2}$ at room temperature, $350^{\circ} \mathrm{C}$, and $450^{\circ} \mathrm{C}$. All these samples were annealed at $600^{\circ} \mathrm{C}$ for $60 \mathrm{~min}$. The $350^{\circ} \mathrm{C}$ implanted samples suffered an extra anneal at $1000^{\circ} \mathrm{C}$ for 30 min. All anneals were done in $\approx 5 \times 10^{-6}$ mbar vacuum.

The in-depth composition of the various samples was determined by the Rutherford backscattering spectrometry (RBS) and elastic recoil detection (ERD) (RBS at $\Theta=140^{\circ}$ and $180^{\circ}$ scattering angle, IBM geometry, $1.6 \mathrm{MeV}{ }^{4} \mathrm{He}^{+}$, $1.5 / 1.73 \mathrm{MeV} \mathrm{H}^{+}$or $\Theta=165^{\circ}$, Cornell geometry, 3.043/3.145/3.8 $\mathrm{MeV}^{4} \mathrm{He}^{+}$; 
ERD at $\Theta=23^{\circ}$, IBM geometry, $3.043 \mathrm{MeV}{ }^{4} \mathrm{He}^{+}$). $1.73 \mathrm{MeV}$ protons are especially sensitive to $\mathrm{C}$ and $3.145 \mathrm{MeV}$ He ions to $\mathrm{O}$ due to the resonances at $1.730 \mathrm{MeV}$ and $3.045 \mathrm{MeV}$. The densification effect of ion-implantation in PS was investigated both by cross-section transmission electron microscopy (XTEM) and the resonance method [7]. The latter procedure measures the porosity of the sample through the enhanced width of the ${ }^{16} \mathrm{O}$ resonance peak. Ion beam analysis data were evaluated with RUMP [8], RBX [9], and NDF [10]. Glancing incidence X-ray diffraction (GIXRD) measurements were done with a Siemens D-5000 diffractometer $\left(1^{\circ}\right.$ or $0.5^{\circ}$ incidence, $\mathrm{Cu} K_{\alpha}$ radiation). Phase identification was based on Refs. [11] and [12] (for $\mathrm{Cr}_{5} \mathrm{Si}_{3}$ ).

Samples for XTEM were prepared by argon ion milling (see details in Ref. [7]) and then investigated with a Philips CM 20 type electron microscope at $200 \mathrm{keV}$ $\mathrm{e}^{-}$energy.

\section{Results and discussions}

\subsection{Porosity change}

Porosity change measurements using the ${ }^{16} \mathrm{O}$ resonance method were carried out on selected virgin and implanted samples. Results obtained in samples implanted with $20 \%$ of the regular fluence show them to be almost completely densified [6]. In higher dose samples, all processes can, therefore, be considered to have occurred in compact material, little influenced by the original structure. The only structure-related difference observed was the "peeling off" of the porous layer in non pre-oxidized spongy samples when implanted at $450^{\circ} \mathrm{C}$. In all other samples, though the surface densifies, the in-depth PS retains its integrity, as shown by the XTEM pictures (Figs. 1a, c, and d).

\subsection{Composition profiles}

Figure 2 shows a set of representative spectra and simulations. The as-implanted profiles were found to be nearly rectangular both for the room temperature (RT) and high temperature implantations (see, for example, Fig. 2c). $\mathrm{Cr}$ and $\mathrm{Co}$ profiles are around $150 \mathrm{~nm}$ and $60 \mathrm{~nm}$ thick, respectively. These thickness values, calculated using Bragg's rule [13], agree well with the ones obtained for Co from the XTEM pictures (see Fig. 1). A diffusion-like tail exists as well, increasing with implantation temperature. The same pictures also reveal increased surface roughness in the high temperature implanted sample.

According to the simulated depth profiles, during implantation, $\mathrm{C}$ and $\mathrm{O}$ were partially expelled from the implanted layer, piling up behind it. In the case of $\mathrm{Cr}$, this process did not occur at $\mathrm{RT}$, indicating that it is related to silicide formation and/or enhanced atom mobility at $450^{\circ} \mathrm{C}$. For $\mathrm{Co}$, the opposite happens: the expelling process is more pronounced at $\mathrm{RT}$, the concentration of retained $\mathrm{O}$ 

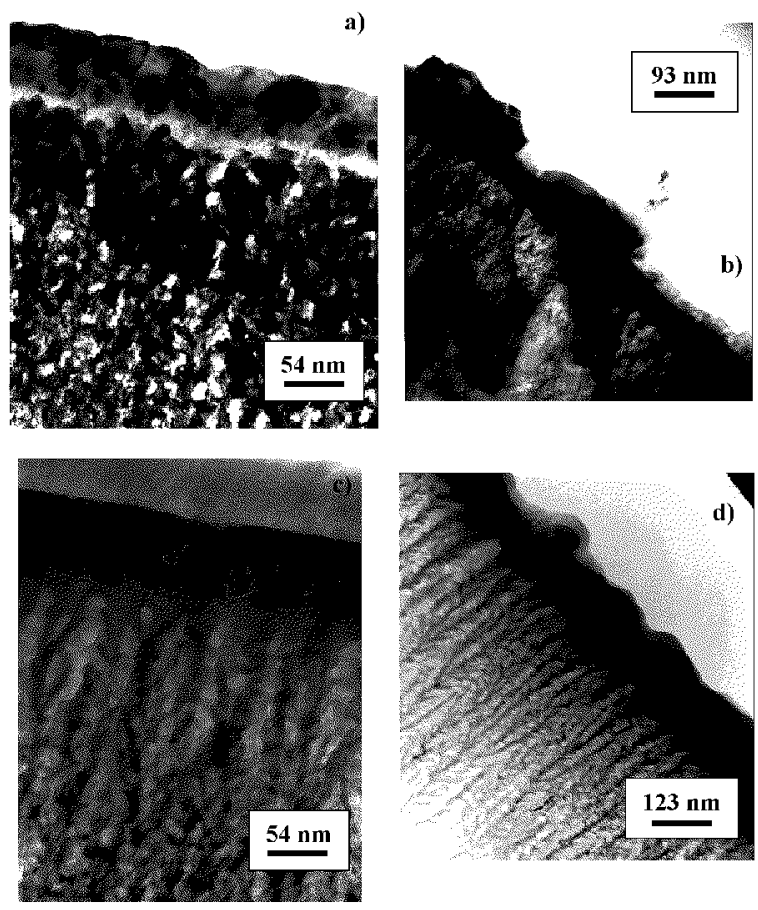

Fig. 1. XTEM pictures of several Co implanted porous samples: (a) columnar type sample of $40 \%$ porosity implanted at $350^{\circ} \mathrm{C}$; (b) the same sample after annealing at $1000^{\circ} \mathrm{C}$; (c) $70 \%$ porosity, pre-oxidized columnar sample implanted at room temperature; (d) the similar sample implanted at $450^{\circ} \mathrm{C}$. The high oxygen content of the latter sample did not allow the growth of large silicide grains as in part (a).

increasing with implantation temperature. Such behaviour may indicate oxygen redistribution in the implanted layer during high temperature implantation, supposedly related to a higher diffusion coefficient and/or solubility of $\mathrm{O}$ in Co silicide. The difference between $\mathrm{Co}$ and $\mathrm{Cr}$ implanted samples indicates that the expelling process is not a ballistic effect, but that it is indeed related to silicide formation: no silicide phases exist in RT implanted samples for $\mathrm{Cr}$, while for $\mathrm{Co}$, $\mathrm{CoSi}$, and $\mathrm{Co}_{2} \mathrm{Si}$ are observed by GIXRD. $\mathrm{H}$ is also removed from the implanted layer (see Fig. 2b).

While for monocrystalline Si the retained ion dose increases with implantation temperature, for PS it decreases. In the case of high temperature implantations, the retained dose decreases with $\mathrm{O}$ content, with higher values in monocrystalline $\mathrm{Si}$ and lower values in heavily contaminated PS samples. Conversely, for the RT implantations, the retained dose increases with the O content. Such behaviour may indicate an oxygen enhanced metal diffusion mechanism towards the surface during high temperature implantation. 


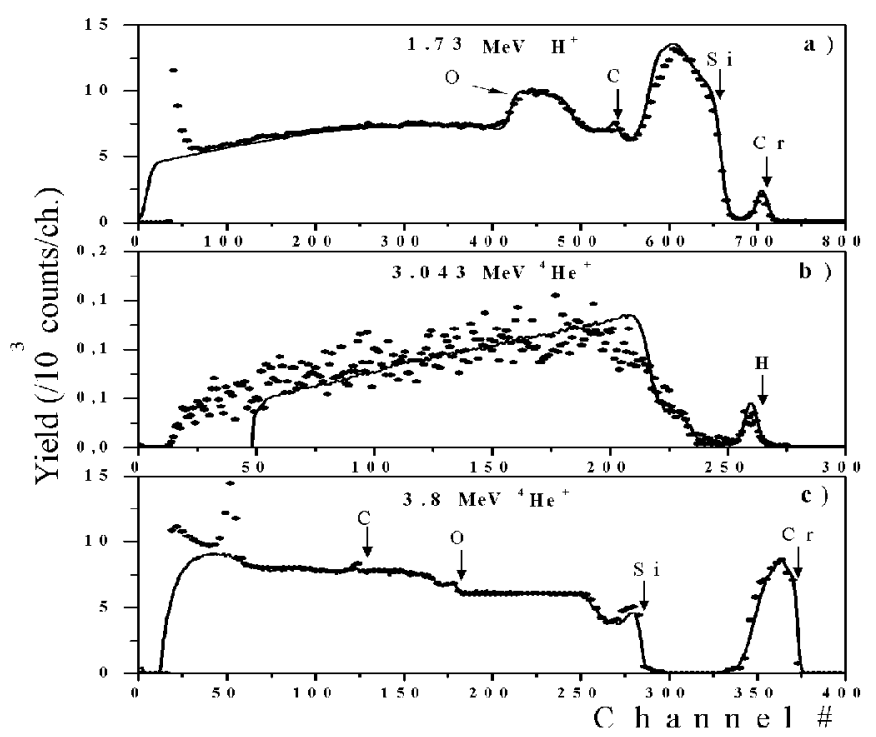

Fig. 2. RBS and ERD spectra for a spongy pre-oxidized sample of $60 \%$ porosity, implanted with $\mathrm{Cr}$ at $450^{\circ} \mathrm{C}$. (a) RBS $1.73 \mathrm{MeV} \mathrm{H}^{+} \Theta=180^{\circ}$, IBM geometry; (b) ERD $3.4043 \mathrm{MeV}^{4} \mathrm{He}^{+}, \Theta=23^{\circ}$, IBM geometry; (c) RBS $3.8 \mathrm{MeV}^{4} \mathrm{He}^{+}, \Theta=165^{\circ}$, Cornell geometry. Dots are measured spectra, while lines correspond to simulations.

\subsection{Phase formation}

The X-ray diffraction data indicate that several silicide phases form, depending on temperature and oxygen content (see Fig. 3). $\mathrm{CoSi}_{2}$ or $\mathrm{CrSi}_{2}$ grow preferably in low oxygen, high temperature implanted samples. The integrated intensity of the diffraction lines and the average grain size of the precipitates decrease as the $\mathrm{O}$ content grows. For $\mathrm{Co}$, at about $0.22 \mathrm{O} / \mathrm{Si}$ ratio another silicide phase appears - CoSi - which disappears at even higher O contents. For such samples, the increasing of the implantation temperature from $350^{\circ} \mathrm{C}$ to $450^{\circ} \mathrm{C}$ does not promote $\mathrm{CoSi}_{2}$ formation (see Fig. 3). $\mathrm{CrSi}_{2}$ formation in high temperature implanted samples continuously decreases until $\approx 0.25 \mathrm{O} / \mathrm{Si}$ ratio, when it disappears. Weak $\mathrm{Cr}_{5} \mathrm{Si}_{3}$ peaks appear in heavily contaminated samples. For the RT implanted samples, $\mathrm{CrSi}_{2}$ disappears already at $\approx 0.03 \mathrm{O} / \mathrm{Si}$ ratio and no other silicide phases are visible. Weak $\mathrm{Cr}$ and $\mathrm{Si}$ oxide lines also appear in highly contaminated samples. No Co oxides or metallic Cr or Co peaks are discernible.

Sheet resistance data indicate that in most samples a low resistivity layer forms in spite of the impurities. In the high temperature Cr implanted samples, the resistance coincides within error to that of $\mathrm{Cr}$ implanted monocrystalline $\mathrm{Si}$; for the RT samples it is always higher. Taking the thickness measured by RBS, the obtained resistivity is $\approx 1300 \mu \Omega \mathrm{cm}$, in good agreement with other values found in literature for IBS $\mathrm{CrSi}_{2}$ [14]. The Co implanted layers are more sensitive 


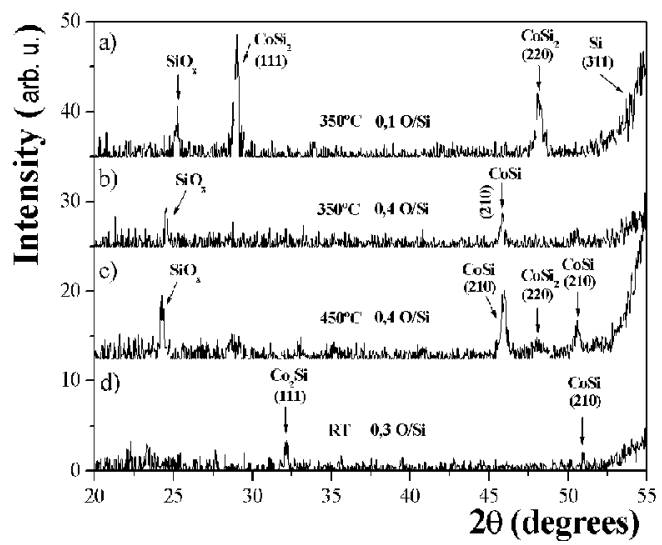

Fig. 3. Glancing incidence X-ray diffraction spectra of several columnar samples implanted with Co at different temperatures. $\mathrm{CoSi}_{2}$ forms in low $\mathrm{O} / \mathrm{Si}$ ratio, high temperature implanted samples (a). Higher $\mathrm{O} / \mathrm{Si}$ ratios result in CoSi forming instead (b). For these samples, increasing the temperature does not efficiently promote $\mathrm{CoSi}_{2}$ formation (c). Room temperature implanted samples show practically no silicide phase but weak $\mathrm{CO}_{2} \mathrm{Si}+\mathrm{CoSi}$ formation (d)

to the original $\mathrm{O}$ content: the sheet resistance increases with the $\mathrm{O} / \mathrm{Si}$ ratio in the implanted layer, but differently for the various temperatures. For lower ratios, the high temperature implanted samples have lower resistivity; above $0.22 \mathrm{O} / \mathrm{Si}$ ratio, the sheet resistance increases faster for the high temperature samples than for the RT ones. This may be the result of coarser $\mathrm{SiO}_{2}$ precipitates in the high temperature samples, though their presence is not easily distinguished in the X-ray diffraction spectra. Best values are around $45 \mu \Omega \mathrm{cm}(\approx 3$ times higher than for layers formed on monocrystalline $\mathrm{Si}$ ).

\subsection{Annealing results}

$\mathrm{X}$-ray diffraction measurements revealed that, up to $0.70 \mathrm{O} / \mathrm{Si}$, annealing promotes the transformation of $\mathrm{CoSi}$ into $\mathrm{CoSi}_{2}$, if the first was present, or the growth of the $\mathrm{CoSi}_{2}$. For even higher O/Si ratios, $\mathrm{CoSi}$ also starts growing. In more contaminated samples, it is the only phase present. Similarly, annealing enhances the $\mathrm{CrSi}_{2}$ content and/or grain size. As the $\mathrm{O}$ content increases, other $\mathrm{Cr}$ rich phases begin to form, namely $\mathrm{Cr}_{5} \mathrm{Si}_{3}$ and even $\mathrm{Cr}_{3} \mathrm{Si}$. As expected, $\mathrm{CrSi}$ is not observed [15]. The sheet resistance slightly increases during the $700^{\circ} \mathrm{C}$ annealing of the $\mathrm{Cr}$ implanted samples, following an increase in $\mathrm{O}$ content in the implanted layer. In the case of high temperature Co implanted samples, annealing at $600^{\circ} \mathrm{C}$ results in lower resistivity. Conversely, for RT implantations, the same annealing results in a resistivity increase for samples of $>0.25 \mathrm{O} / \mathrm{Si}$. The additional $1000^{\circ} \mathrm{C}$ annealing induces a dramatic structure modification as shown in Fig. 1b: 
large isolate silicide precipitates grow and the underlying porous silicon is severely damaged, which results in increased resistivity for all samples.

\section{Conclusions}

In spite of the high impurity level of PS, we were able to form a good quality polycrystalline silicide film in most samples. Best results are obtained by high temperature implantations, where the impurities are partially expelled from the forming silicide, piling up behind it. Very high oxygen contents inhibit silicide formation. Under the experimental conditions used, in porous silicon with an O/Si ratio $<0.22$ (for $\mathrm{Co}$ ) or $<0.25$ (for $\mathrm{Cr}$ ), it is possible to form a good quality disilicide layer immediately during implantation. In more contaminated substrates, other more metal rich phases appear. Above $0.70 \mathrm{O} / \mathrm{Si}$ ratio no silicide can be detected by X-ray diffraction. Lower resistivity values are obtained for Co, with the $350^{\circ} \mathrm{C}$ implanted samples, though their resistivity is still $\approx 3$ times higher than that of their monocrystalline counterpart ( 15 vs. $45 \mu \Omega \mathrm{cm}$ ). The $1000^{\circ} \mathrm{C}$ annealing results in the destruction of the underlying porous silicon and the growth of large isolated silicide precipitates.

\section{Acknowledgments}

This work was supported by the Hungarian-Portuguese bilateral intergovernmental cooperation TéT P-14/97 and ICCTI 423/OMFB. A.R.R. would like to acknowledge grant BDP/3557/2000 from FCT, Portugal.

\section{References}

[1] Porous Silicon Science and Technology, Eds. J.C. Vial, J. Derrien, Springer-Verlag, Berlin 1995.

[2] F. Pászti, A. Manuaba, E. Szilágyi, É. Vázsonyi, Z. Vártesy, Nucl. Instrum. Methods Phys Res. B 117, 253 (1996).

[3] S.P. Murarka, Silicides for VLSI, Academic Press, New York 1985.

[4] E. Cattaruzza, G. Mattei, P. Mazzoldi, R. Bertocello, G. Battaglin, L. Mirenghi, Appl. Phys. Lett. 67, 2884 (1995).

[5] A.R. Ramos, O. Conde, F. Pászti, G. Battistig, É. Vázsonyi, M.R. da Silva, M.F. da Silva, J.C. Soares, Nucl. Instrum. Methods Phys. Res. B 161-163, 926 (2000).

[6] É. Vázsonyi, M. Koós, G. Jalsovszky, I. Pócsik, J. Lumin. 57, 121 (1993).

[7] F. Pászti, E. Szilágyi, Zs. Horváth, A. Manuaba, G. Battistig, Z. Hajnal, E. Vázsonyi, Nucl. Instrum. Methods Phys. Res. B 136-138, 533 (1998).

[8] L.R. Doolittle, Nucl. Instrum. Methods Phys. Res. B 5, 344 (1985).

[9] E. Kótai, Nucl. Instrum. Methods Phys. Res. B 85, 588 (1994). 
[10] N.P. Barradas, C. Jeynes, R.P. Webb, Appl. Phys. Lett. 71, 291 (1997).

[11] Joint committee on Powder Diffraction Standards, Powder Diffraction File, ASTM, Philadelphia 1992.

[12] E. Mazzega, M. Michelini, F. Nava, J. Phys. F 17, 1135 (1987).

[13] Handbook of Modern Ion Beam Materials Analysis, Eds. J.R. Tesmer, M. Nastasi, MRS, Pittsburgh 1995.

[14] Chr. Dudda, S. Mantl, Ch. Dieker, M. Dolle, H. Lüth, Nucl. Instrum. Methods Phys. Res. B 80-81, 764 (1993).

[15] R. Pretorius, Thin Solid Films 290-291, 477 (1996). 